\title{
Study of double rotor speed-regulating wind power generation system
}

\author{
Yanan Li, Peng Yang ${ }^{*}$ and Huajun Wang
}

\begin{abstract}
Large-scale wind turbines have become the trend of the wind power industry. However, the main factors restricting the large scale wind turbines are frequent replacement of carbon brush and slip ring and the harmonic of the stator current in double-fed induction generator, plus converters' large volume, high cost, and high failure rate in full power converter of wind turbine. Therefore, new double rotor speed-regulating wind power generation system comprising a double rotor speed-regulating device connected to the gearbox and the synchronous generator is proposed for the sake of lower cost, higher reliability, and stronger adaptability of the power grid. The structure of the system and the connection of each component are described; meanwhile, the working principle of the system under different operating conditions is analyzed. Furthermore, the mathematical model of the system is established, besides the control strategy being proposed. The simulation results verify the correctness of the mathematical model and the control strategy.
\end{abstract}

Keywords: Wind power, Double rotor generator, Speed-regulating device, Mathematical model, Large-scale wind turbines, Grid adaptability

\section{Introduction}

Wind power has become an important object of R\&D around the world as an effective measure to solve the current energy crisis and environmental contamination. Nevertheless, double-fed induction generator (DFIG) and permanent magnetic synchronous generator (PMSG) have the disadvantages of poor grid-connected capacity when the wind turbines become large scale.

Internet of things relies on the development of technology referred to as $\mathrm{ABC}$ : $\mathrm{A}$ is artificial intelligence, $\mathrm{B}$ is big data, and $C$ refers to cloud computing. For the wind power market, it is necessary to rely on $A B C$ technology, combined with the characteristics of the wind power industry, in order to be in the dominant position in the market competition. First of all, in the artificial intelligence, the amount of data and the complexity of the algorithm will be greatly improved. The simulation data will also be included in the sequence of calculation and training, which makes the speed of intelligence faster, and the intelligence of the equipment on this basis will be more and more high. Meanwhile, big data will no

* Correspondence: yphebut@163.com

School of Artificial Intelligence, Hebei University of Technology, Tianjin, China longer be a single list of concepts, but will become the core of the infrastructure, and the automatic data generated by the device (including human self) will be far more than the data generated by human social behavior, cloud to end, end to end, cloud to cloud, and big data will be ubiquitous in the way of network. Furthermore, with the increase of mass data and the increasing demand of machine learning for real time, and the high coupling of business logic, the way of public cloud will no longer fit the Internet of things. The mode of mini data center will replace the public cloud. The data decision processing will be closer to the data source, and the edge computing will become the mainstream. Therefore, the real-time nature of the Internet of things will make the operation of the wind power more intelligent and will have a far-reaching impact on the change of the wind power service industry.

As far as the DFIG is concerned, the use of the high variable ratio gearbox increases the failure rate of the wind turbine generator system to reduce the reliability [1]. Meanwhile, the carbon brushes and slip rings are available in the generator rotor [2]. In general, the carbon brush is replaced every 6 months and the slip ring is replaced every 2 years, resulting in the high maintenance 
frequency and high cost [3]. Moreover, the generator stator is directly connected with the power grid, plus the rotor current is in constant change, so the stator output current is more harmonic and difficult to control [4]. The inflow of the harmonic current to the power grid will cause the following negative effects [5]. Firstly, the harmonics increase the loss of transmission lines and transformers, accelerate the insulation aging of the equipment, shorten the service life, and even lead to equipment scrapping [6]. Secondly, the harmonic causes the protection device malfunction, which leads to the inaccuracy of the electrical measurement instrument [7]. Thirdly, the harmonic leads to the local parallel or series resonance of the power grid to further amplify the harmonics, and then results in the instability of the power grid [8].

Compared with DFIG, PMSG has no carbon brush and slip ring, so the maintenance performance is better than DFIG [9]. Specifically, the harmonic frequency of the stator output current is stable and easy to control [10]. Besides, the generator and the power grid are isolated by the full power converter, so there is no current impact and the power grid adaptability is stronger [11]. However, due to the use of the full power converter, the converter has large capacity, large volume, and high loss, which brings about high cost of manufacturing and operation [12]. In addition, the converter has been the higher failure rate component of the PMSG, which reduces the reliability and increases the maintenance cost of the PMSG [13].

Therefore, the new concept of speed-regulating wind turbine is presented. That is to say, variable wind speed is regulated to a constant speed by the speed-regulating device between the wind turbine and the generator, so synchronous is driven to output constant frequency electric power.

A new type of variable speed constant frequency wind turbine which combines the hydraulic coupling speedregulating device called Windrive with the conventional synchronous generator has been proposed by Dewind [14]. The working principle is shown in Fig. 1.

Windrive is a speed controller composed of planetary gear and torque converter, which is responsible for connecting the high-speed shaft of the gearbox and the constant speed synchronous generator shaft to ensure the variable speed constant frequency operation of the wind turbine and capture the maximum wind energy [15].

But the Windrive also has existing weaknesses. Firstly, the hydraulic torque converter absorbs the energy from the power grid to regulate the speed in lower wind speed period of time, which reduces the generating efficiency [16]. Secondly, the hydraulic torque converter is generally required for the operating environment, so its applicability in the harsh natural environment of the wind farm remains to be verified [17]. Thirdly, variable speed constant frequency operating range of wind turbine with hydraulic torque converter is restricted [18]. Fourthly, the manufacturing cost of the torque converter is high, which leads to the failure of mass production.

Therefore, a new type of variable speed constant frequency wind turbine based on the electromagnetic coupler has been proposed by Tsinghua University. The hydraulic coupling device has been replaced by frequency control electromagnetic coupler, so that the high-speed output shaft of the gear box is connected with the generator shaft in a noncontact way. The structure is shown in Fig. 2.

The advantages of the wind turbine with electromagnetic coupler are as follows: firstly, the wind turbine can carry out stepless speed regulation due to non-contact flexible drive device like electromagnetic coupler [19]. Secondly, the speed-regulating range of the wind turbine is wider, and the utilization rate of wind energy is higher in lower wind speed period of time [20]. Thirdly, the response speed of the wind turbine is fast and the adjustment is stable due to the transfer torque of the electromagnetic coupler controlled by converter [21].

However, the volume and weight of the wind turbine are equivalent to about two times that of the same capacity wind turbine by using electromagnetic coupler replaced hydraulic torque converter, which increases the difficulty of transportation and lifting. Furthermore, only can the electromagnetic coupler achieve speed regulation through adjusting the torque and speed of the wind turbine, so the generating efficiency of wind turbine needs to be improved. In addition, the high cost of electromagnetic coupler is also a crucial factor which restricts mass production of the electromagnetic coupling speed-regulating wind turbine.

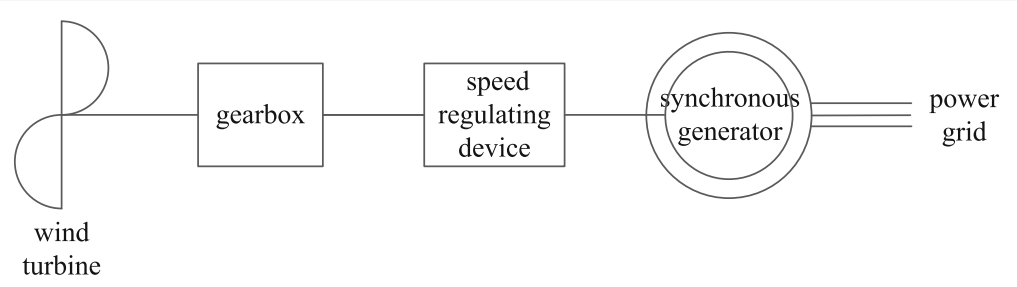

Fig. 1 Speed-regulating wind turbine structure diagram 


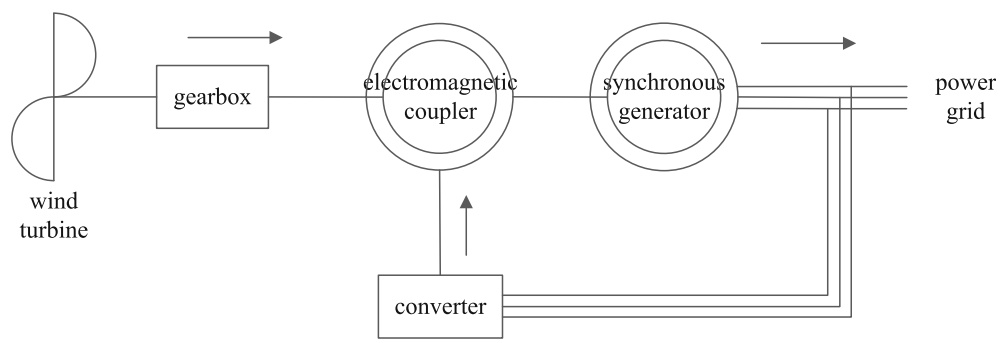

Fig. 2 Electromagnetic coupling speed-regulating wind turbine structure diagram

Based on the analysis of the characteristics of two kinds of speed-regulating wind turbines mentioned above, a new type of driving chain of speed-regulating wind turbine is proposed in this paper, which achieves speed regulating and generating simultaneously in a certain period of time to reduce the capacity of generator and converter. Moreover, the range of variable speed constant frequency of the wind turbine is wider, and the generating efficiency and reliability are improved on the basis of stronger grid adaptability.

\section{Structure of the double rotor speed-regulating wind power generation system}

The structure of the double rotor speed-regulating wind power generation system is shown in Fig. 3. It is mainly composed of the wind wheel, gearbox, double rotor speed-regulating generator, electric excitation synchronous generator, converter, rectifier, transformer, and switch. The double rotor speed-regulating generator comprises a permanent magnet outer rotor and a wound inner rotor. The permanent magnet outer rotor is mechanically connected to the gear box, besides the wound inner rotor is coaxially connected with the rotor of electric excitation synchronous generator as well as is electrically connected with the converter.

\section{Working principle and operation state of double rotor speed-regulating wind power generation system}

3.1 Working principle

The rotational speed of the double rotor speed-regulating generator can be obtained as shown in formula (1) since the rotating magnetic field formed by inner and outer rotor of the speed-regulating generator must remain relatively static to achieve stable mechanical and electrical energy conversion according to the electromechanical principle.

$$
n_{\mathrm{out}}=n_{\mathrm{in}}+n_{\mathrm{f}}
$$

where $n_{\text {out }}$ is the rotational speed of the outer rotor under external forces, $n_{\text {in }}$ is the mechanical speed of the inner rotor, and $n_{\mathrm{f}}$ is the rotational speed of the rotating magnetic field generated by the current from the wound inner rotor.

The power of the double rotor speed-regulating generator can be obtained as shown in formula (2) according to the energy conservation law.

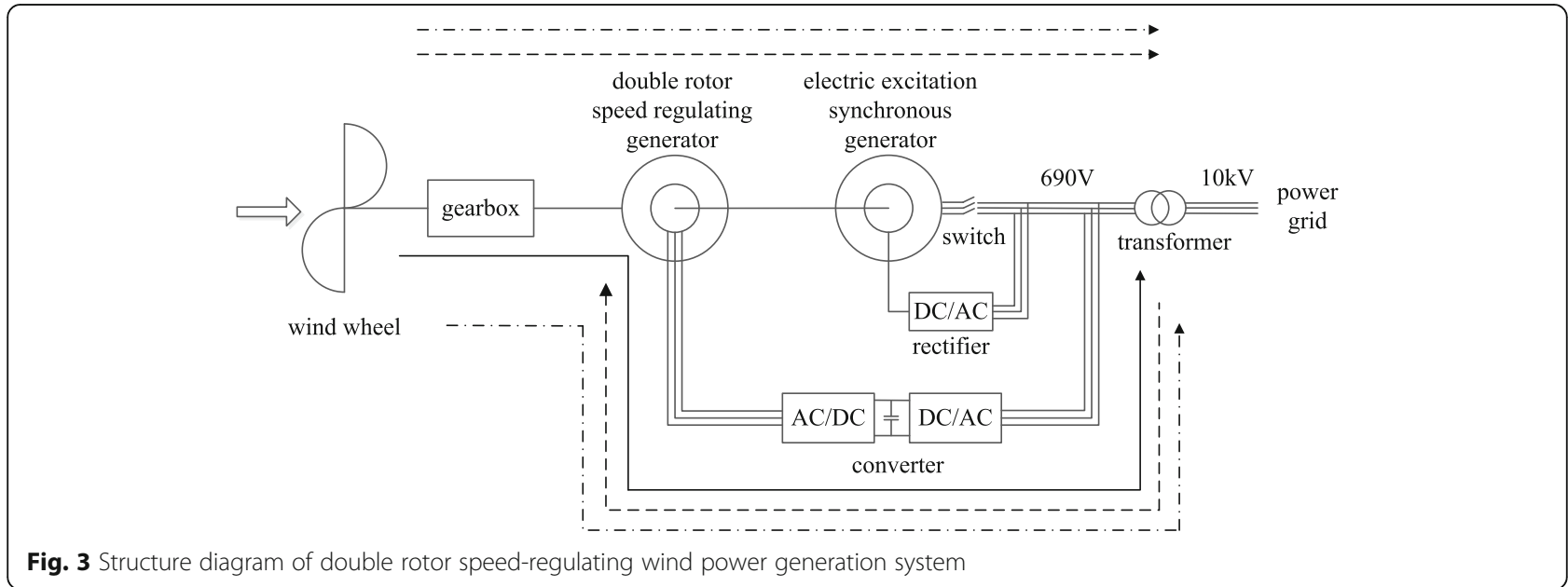




$$
P_{\mathrm{m}}+P_{\mathrm{f}}=P_{\mathrm{L}}
$$

where $P_{\mathrm{m}}$ is the input mechanical power of the speedregulating generator, $P_{\mathrm{f}}$ is the electrical power of the speed-regulating generator, and $P_{\mathrm{L}}$ is the output mechanical power of the speed-regulating generator.

The torque transmission of the speed-regulating generator as shown in formula (3) can be deduced by the formula (2).

$$
T_{\mathrm{m}} \omega_{\text {out }}+T_{\mathrm{e}} \omega_{\mathrm{f}}=T_{\mathrm{L}} \omega_{\text {in }}
$$

where $\omega_{\text {out }}$ and $\omega_{\text {in }}$ are the mechanical angular velocity of the outer and inner rotor of the speed-regulating generator respectively, $\omega_{\mathrm{f}}$ is the angular velocity of the rotating magnetic field formed by the current of the wound inner rotor, $T_{\mathrm{e}}$ is the electromagnetic torque of the speed-regulating generator, and $T_{\mathrm{m}}$ and $T_{\mathrm{L}}$ are the input and output mechanical torque of the speed-regulating generator respectively.

The electromagnetic torque expression of the speedregulating generator as shown in formula (4) can be derived from the formula (3).

$$
T_{\mathrm{e}}=\frac{T_{\mathrm{L}} \omega_{\text {in }}-T_{\mathrm{m}} \omega_{\text {out }}}{\omega_{\text {out }}-\omega_{\text {in }}}
$$

It is known by the formula (4) that the electromagnetic torque of the speed-regulating generator declines logarithmically with the increase of the inner and outer rotor speed.

\subsection{Operating state}

Five operating states of the double rotor speed-regulating wind power generation system are as follows:

State I Speed-regulating generator generates electricity State II Speed-regulating generator speed regulating State III Speed-regulating generator speed regulates and generates electricity simultaneously

State IV Constant speed-operating state

State V Constant power-operating state (rated operating state)

\subsubsection{State I}

The inner rotor of the speed-regulating generator coaxially connected with the rotor of the synchronous generator is equivalent to a stator because the synchronous generator is not connected with the power grid. That means the system is equivalent to the full-power converter wind turbine generator with permanent magnet outer rotor and wound inner stator.

The outer rotor speed $n_{\text {out }}$ of the speed-regulating generator increases from zero with the rise of wind speed $v$ since the wind speed reaches cut in value $v_{\mathrm{in}}$, and the output power of the speed-regulating generator to the power grid is $P_{\mathrm{f}}$. The synchronous generator is connected with the power grid as soon as $P_{\mathrm{f}}$ reaches the rated power $P_{\mathrm{fN}}$ of the speed-regulating generator. From this moment on, the system will operate in the state II, and the wind speed of this moment is $v_{1}$.

The power flow of the system in the state I is as shown in the solid line in Fig. 3. The wind energy absorbed by the wind wheel is converted to electricity by the speed-regulating generator and then transferred to the power grid.

\subsubsection{State II}

The outer rotor speed $n_{\text {out }}$ continually increases with the rise of the wind speed since the wind speed exceeds $v_{1}$. The inner rotor of the speed-regulating generator coaxially connected with the rotor of the synchronous generator starts to rotate as the synchronous generator is connected with the power grid, that is, the inner rotor speed $n_{\text {in }}$ increases from zero. The frequency $f$ of the inner rotor winding current is regulated and controlled in order that the inner rotor speed $n_{\text {in }}$ rapidly reaches and stabilizes at the synchronous speed $n_{0}$, that is $n_{\text {out }}<n_{\text {in }}=n_{0}$. The speed-regulating generator is in the state of speed regulating as the converter absorbs active power from the power grid to the speed-regulating generator, that is to say, the output power of the speed-regulating generator is positive, $P_{\mathrm{f}}>0$, besides the output power $P_{\mathrm{f}}$ of the speed-regulating generator first increases and then decreases with the speed difference between the inner and outer rotor. The converter provides DC excitation for the speed-regulating generator as soon as the outer rotor speed $n_{\text {out }}$ increases to the synchronous speed $n_{0}$ with the rise of the wind speed, that is, $n_{\text {out }}=n_{\text {in }}=n_{0}, P_{\mathrm{f}}=0$. From this moment on, the system will operate in the state III, plus the wind speed of this moment is $v_{2}$.

The power flow of the system in the state II is as shown in the dotted line in Fig. 3. The wind energy absorbed by the wind wheel and speed regulated through the speed-regulating generator is transferred to the synchronous generator and then transported to the power grid. Simultaneously, the converter absorbs part of the power from the grid to provide to the speed-regulating generator.

\subsubsection{State III}

The outer rotor speed $n_{\text {out }}$ continues to increase with the wind speed rising since the wind speed exceeds $v_{2}$. That is $n_{\text {out }}>n_{\text {in }}=n_{0}$. The speed-regulating generator is in the state of speed regulating and generating electricity as it outputs active power to the power grid through the converter, that is to say, the output power of the speed-regulating generator is negative, $P_{\mathrm{f}}<0$, besides the absolute value of the output power $\left|P_{\mathrm{f}}\right|$ of the 
speed-regulating generator increases with the speed difference between the inner and outer rotor. The system will operate in the state IV as soon as the outer rotor speed increases to its rated speed with the wind speed rising, that is, $n_{\text {out }}=n_{\text {outN }}$, and the wind speed of this moment is $v_{\omega \mathrm{N}}$.

\subsubsection{State IV}

The outer rotor speed $n_{\text {out }}$ has already reached the rated value $n_{\text {outN }}$ since the wind speed exceeds $v_{\omega \mathrm{N}}$, whereas the output power $P_{\mathrm{f}}$ of the speed-regulating generator has not reached the rated value $P_{\mathrm{fN}}$; thus, the output power $P_{\mathrm{f}}$ continues to increase as the wind speed rises while the outer rotor speed keeps stable. The system operates in the constant power operation state as soon as the output power of the speed-regulating generator is increased to the rated value $P_{\mathrm{fN}}$. From this moment on, the system will operate in the state $\mathrm{V}$, and the wind speed of this moment is $v_{\mathrm{N}}$.

\subsubsection{State $V$}

The system operates in the rated operating state by adjusting the pitch angle to limit the wind energy captured by the wind wheel since the wind speed exceeds $v_{N}$. That is to say, the outer rotor speed of the speed-regulating generator is the rated speed $n_{\text {outN }}$, besides the output power of the speed-regulating generator is the rated power $P_{\mathrm{fN}}$. In addition, the output power of the synchronous generator is the rated power $P_{\mathrm{SN}}$.

The power flow of the system in the states III to V is as shown in the dash-dotted line in Fig. 3. A part of the wind energy absorbed by the wind wheel and speed regulated through the speed-regulating generator is transferred to the synchronous generator and then transported to the power grid. Meanwhile, the other is converted to electricity through the converter and then transferred to the power grid. In this way, a double feeder of electricity is realized.

The synchronous generator provides the rated power $P_{\mathrm{SN}}$ to the power grid as the rotor speed $n_{\mathrm{r}}$ reaches the rated speed $n_{0}$ in the states II to V.

The trend of the speed and power of the double rotor speed-regulating wind power generation system under different wind speeds is as shown in Fig. 4.

\section{Mathematical model and control strategy of the double rotor speed-regulating generator}

\subsection{Mathematical model}

Referring to the mathematical model of the PMSG, taking the inner rotor of the double rotor speed-regulating generator as the reference coordinate, the mathematical model of the double rotor speed regulating generation, the dq coordinate system is established, such as the voltage and

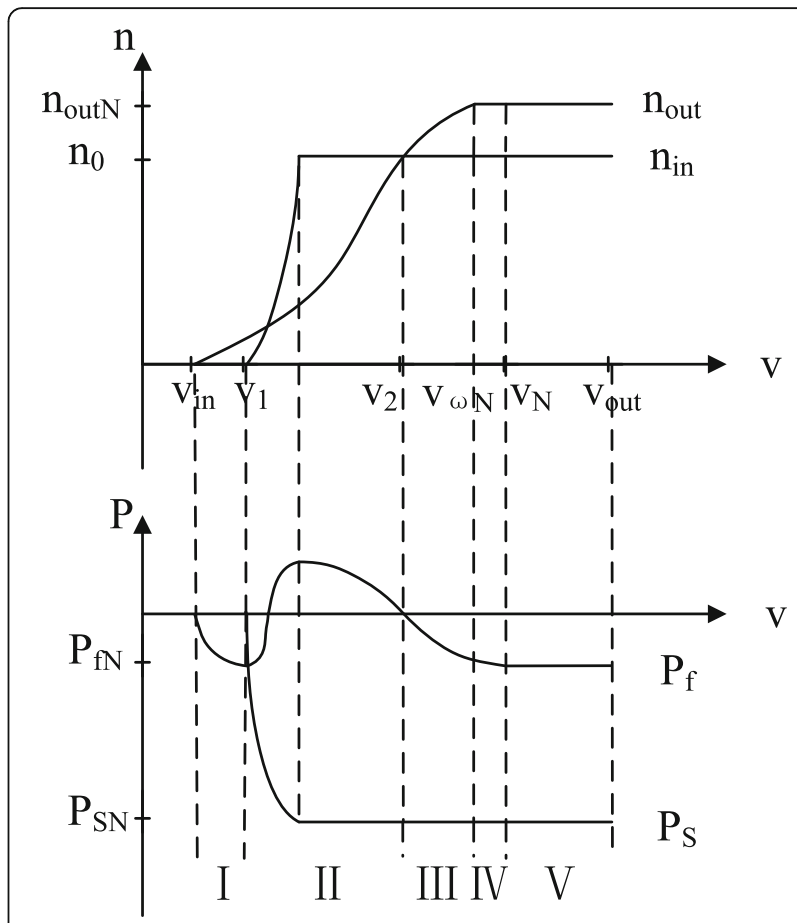

Fig. 4 Speed and power of the double rotor speed-regulating wind power generation system. In Fig. $4, v$ is the wind speed, $n_{\text {out }}$ is the rotational speed of the outer rotor, $n_{\text {outn }}$ is the rated rotational speed of the outer rotor, $n_{\text {in }}$ is the mechanical speed of the inner rotor, $n_{0}$ is the synchronous speed, $P_{\mathrm{f}}$ is the electrical power of the speed regulating generator, $P_{\mathrm{fN}}$ is the rated electrical power of the speed regulating generator, $P_{\mathrm{S}}$ is the output power of the synchronous generator, and $P_{\mathrm{SN}}$ is the rated output power of the synchronous generator

current equation is shown in (5) and (6), the torque equation is shown in (7), and the motion equation is shown in (8) and (9). The dq coordinate system is rotated by the rotational speed difference between the inner and outer rotor, that is $\omega_{\text {out }}-\omega_{\text {in }}$.

$$
\begin{gathered}
u_{d}=R i_{d}+L_{d} \frac{d i_{d}}{d t}-p\left(\omega_{\mathrm{out}}-\omega_{\mathrm{in}}\right) L_{q} i_{q} \\
u_{q}=R i_{q}+L_{q} \frac{d i_{q}}{d t}+p\left(\omega_{\mathrm{out}}-\omega_{\mathrm{in}}\right) L_{d} i_{d} \\
+p\left(\omega_{\text {out }}-\omega_{\mathrm{in}}\right) \psi_{\mathrm{f}}
\end{gathered}
$$

$$
\begin{aligned}
& T_{\mathrm{e}}=\frac{3}{2} p i_{q}\left[\left(L_{d}-L_{q}\right) i_{d}+\psi_{\mathrm{f}}\right] \\
& J_{\text {out }} \frac{d \omega_{\text {out }}}{d t}=T_{\mathrm{m}}-T_{\mathrm{e}} \\
& J_{\text {in }} \frac{d \omega_{\text {in }}}{d t}=T_{\mathrm{e}}-T_{\mathrm{L}}
\end{aligned}
$$

where $u_{d}$ and $u_{q}$ are the $d q$ axis components of the 
terminal voltage (phase voltage) of the inner rotor, respectively. $i_{d}$ and $i_{q}$ are the $d q$ axis components of the inner rotor current, respectively. $R$ is the inner rotor resistance. $L_{d}$ and $L_{q}$ are the $d q$ axis components of the inner rotor inductance, respectively. $\omega_{\text {out }}$ and $\omega_{\text {in }}$ are the mechanical angular velocity of the outer and inner rotor, respectively. $p$ is the pole pairs of the double rotor speed-regulating generator. $\psi_{\mathrm{f}}$ is the flux of the outer rotor permanent magnet. $T_{\mathrm{e}}$ is the electromagnetic torque of the double rotor speed-regulating generator. $T_{\mathrm{m}}$ and $T_{\mathrm{L}}$ are the input and output torque of the double rotor speed-regulating generator, respectively. $J_{\text {in }}$ and $J_{\text {out }}$ are the moment of inertia of the inner and outer rotor, respectively.

\subsection{The control strategy of the outer rotor}

According to the different wind speed, the control strategy of the outer rotor of the double rotor speed-regulating generator is as follows. The maximum power point tracking (MPPT) control strategy is adopted when the wind speed is lower than the rated wind speed. (State I to state IV) The outer rotor can get the optimal torque by controlling the active component of the inner rotor current to ensure that the double rotor speed-regulating wind power generation system operates in the state of maximum wind energy capture. The pitch control strategy is adopted when the wind speed exceeds the rated wind speed. (State V) The output power of the system can be limited in the vicinity of the rated power by adjusting the pitch angle since the mechanical strength and generator capacity are limited.

\subsubsection{Maximum power point tracking (MPPT) control strategy}

The vector control strategy of $i_{d}=0$ is adopted in this paper. When $i_{d}=0$, the torque equation of the double rotor speed-regulating generator is shown in formula (10) according to the formula (7).

$$
T_{\mathrm{e}}=\frac{3}{2} p i_{q} \psi_{\mathrm{f}}
$$

The formula (10) shows that the torque of the double rotor speed-regulating generator is only related to the $q$ axis current. Therefore, controlling the $q$ axis current can control the torque of the double rotor speed-regulating generator and then control the outer rotor to track the maximum power point.

The outer rotor maximum power point tracking control structure diagram is shown in Fig. 5. The double closed loop control strategy with speed outer loop and current inner loop is adopted $\left(\omega_{\mathrm{f}}=\omega_{\text {out }}-\omega_{\text {in }}\right)$.

The speed deviation is obtained by comparing the reference speed signal $\omega_{\mathrm{f}}^{*}$ with the feedback speed signal $\omega_{\mathrm{f}}$, and then input the speed deviation to the speed controller to get the reference torque current signal $i_{q}^{*}$. The current deviation of the $q$ axis and the $d$ axis are respectively obtained by comparing the reference current signal $i_{q}^{*}$ and $i_{d}^{*}=0$ with the feedback current signal $i_{q}$ and $i_{d}$, respectively, and then input the current deviation to respective current controller to get the reference voltage signal $u_{q}^{*}$ and $u_{d}^{*}$. After that $u_{\alpha}$ and $u_{\beta}$ are obtained from coordinate transformation to get the driving signal of the dual PWM converter by SVPWM modulating.

\subsubsection{Pitch control strategy}

The power captured by the wind turbine is maintained at a constant value by the variable pitch control mechanism in order to avoid the damage to the wind turbine in the process of the system transmitting the rated power to the grid when the wind speed exceeds the rated wind speed but is lower than the cut-out wind speed. The blade will be gradually rotated to the tailwind direction with the wind speed increasing. The pitch control structure diagram is shown in Fig. 6.

In Fig. $6, \omega_{\text {outN }}$ is the outer rotor rated angular velocity of the double rotor speed-regulating generator.

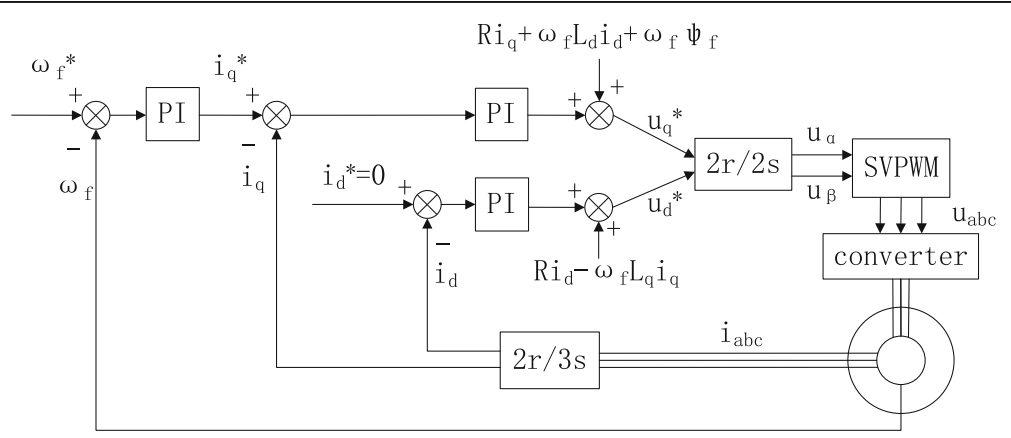

Fig. 5 Structure of outer rotor maximum power point tracking control 


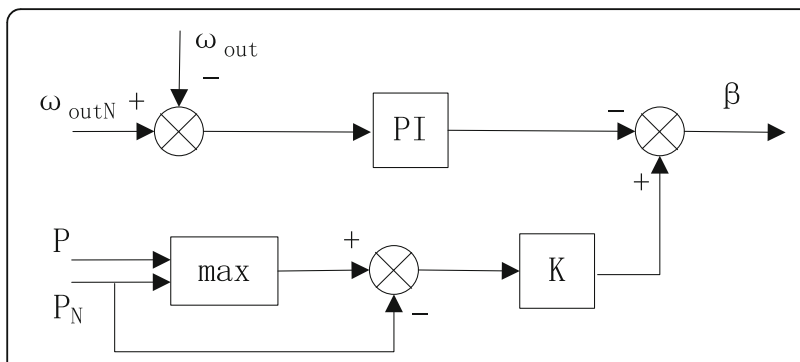

Fig. 6 Pitch control structure

$\omega_{\text {out }}$ is the outer rotor actual angular velocity of the double rotor speed-regulating generator. $P_{\mathrm{N}}$ is the rated output power of the system. $P$ is the actual output power of the system. max is the larger value in $P_{\mathrm{N}}$ and $P$. The regulation of $\beta$ is divided into two ways. One is to control the difference between the outer rotor rated speed and its actual speed of the double rotor speed-regulating generator with PI controller. The other is to control the difference between the larger value in actual power and rated power and the rated power of the double rotor speed-regulating generator with proportional controller. The outer rotor speed and the output power of the double rotor speed-regulating wind power generation system are maintained at the rated value by increasing the pitch angle to reduce the wind turbine airfoils $C_{\mathrm{p}}$ when the outer rotor actual speed exceeds the rated speed or the system actual output power exceeds the rated output power.

\section{Experimental}

The simulation is carried out in MATLAB/Simulink based on the mathematical model of the double rotor speed-regulating generator and the outer rotor control strategy. The simulation parameters are as follows: the rated wind speed is $12 \mathrm{~m} / \mathrm{s}$, the impeller radius is $40 \mathrm{~m}$, the pitch angle is zero, the rated speed of the wind turbine is $23 \mathrm{r} / \mathrm{min}$, the rated power of the double rotor speed regulating generator is $500 \mathrm{~kW}$, and the rated voltage is $690 \mathrm{~V}$.

The double rotor speed-regulating wind power generation system will operate in the state II when the wind speed reaches $7 \mathrm{~m} / \mathrm{s}$ by calculating, so the trend of wind speed is set as shown in Fig. 7.

The trend of outer rotor speed of the double rotor speed-regulating generator with the wind speed change is shown in Fig. 8.

The power of the double rotor speed-regulating generator is shown in Fig. 9.

\section{Results and discussion}

From Fig. 8, we can see that the outer rotor speed can track the change of the wind speed quickly and accurately to achieve the maximum wind energy tracking under the maximum power point tracking control. Therefore, the correctness of the control strategy is verified.

In combination with Figs. 8 and 9, it is known that before $3.75 \mathrm{~s}, \omega_{\text {out }}<\omega_{\text {in }}(157 \mathrm{rad} / \mathrm{s}), P_{\mathrm{f}}>0$, so the double rotor speed-regulating generator is in powerdriven state and absorbs active power from the power grid. During the period of $3.75 \sim 5 \mathrm{~s}, \omega_{\text {out }}>\omega_{\text {in }}$ $(157 \mathrm{rad} / \mathrm{s}), P_{\mathrm{f}}<0$, so the double rotor speed-regulating generator is in generation state and sends out active power to the power grid. At the time of $8 \mathrm{~s}$, the wind speed is abrupt, and the double rotor speed-regulating generator is switched from the generation $\left(P_{\mathrm{f}}<0\right)$ to power-driven $\left(P_{\mathrm{f}}>0\right)$ state.

This paper only discusses the control strategy of the outer rotor of the double rotor speed-regulating

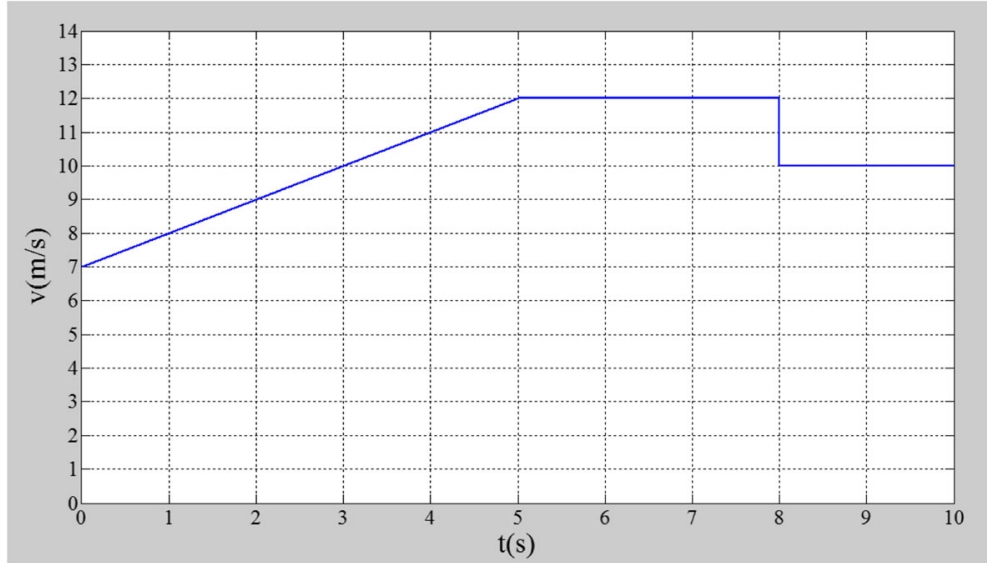

Fig. 7 Wind speed curve. In Fig. 7, X-axis is time (s) and $Y$-axis is wind speed $(\mathrm{m} / \mathrm{s})$ 


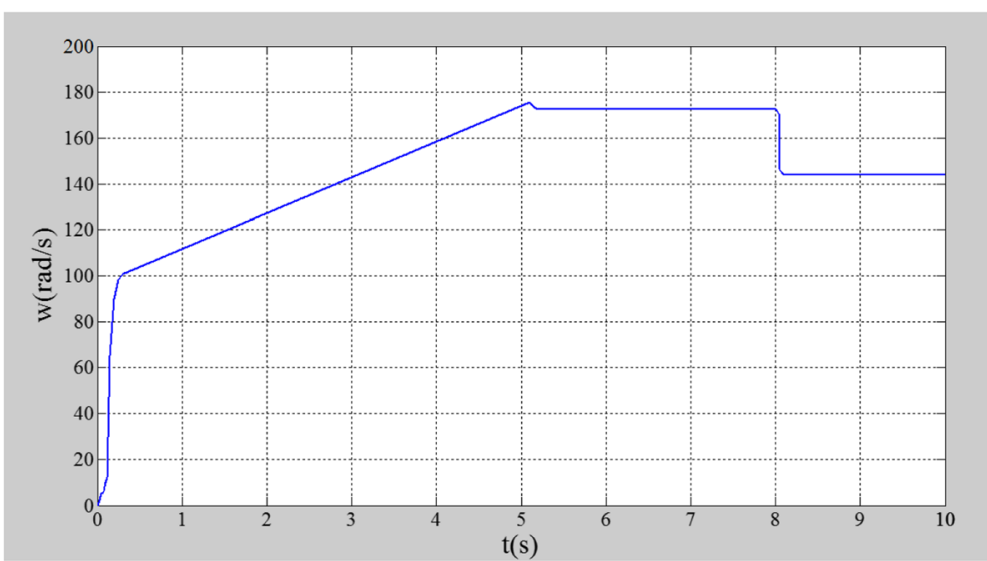

Fig. 8 Outer rotor speed of the double rotor speed-regulating generator. In Fig. 8, X-axis is time (s) and Y-axis is outer rotor speed (rad/s)

generator under the rated wind speed, and the control strategy of the system for the whole wind speed range is still to be studied.

\section{Conclusions}

The double rotor speed-regulating wind power generation system has the ability of speed regulation and power generation at the same time in a certain period of time and reduces the capacity of the generator and converter as a new type of driving chain of speedregulating wind turbine. Moreover, the system can realize the capability of active power overload and reactive power support of the power grid since the synchronous generator is directly connected with the power grid at the end of the driving chain. Furthermore, the variable speed constant frequency operation of the system in the whole wind speed range is guaranteed by multimode operating state under different wind speeds so as to capture the maximum wind power. In addition, the damage of the synchronous generator caused by wind speed fluctuation is reduced as the double rotor speed-regulating generator connecting the gearbox and the synchronous generator, so the reliability of the system is improved. Therefore, the double rotor speed-regulating wind power generation system has a wide application prospect to alleviate the energy crisis and respond to the worsening natural environment.

The research only discusses the PI control strategy of the outer rotor of the double rotor speed-regulating generator under the rated wind speed, and the control strategy of the system for the whole wind speed range is still to be studied. In addition, the transient process of different operating state needs to be studied. Besides,

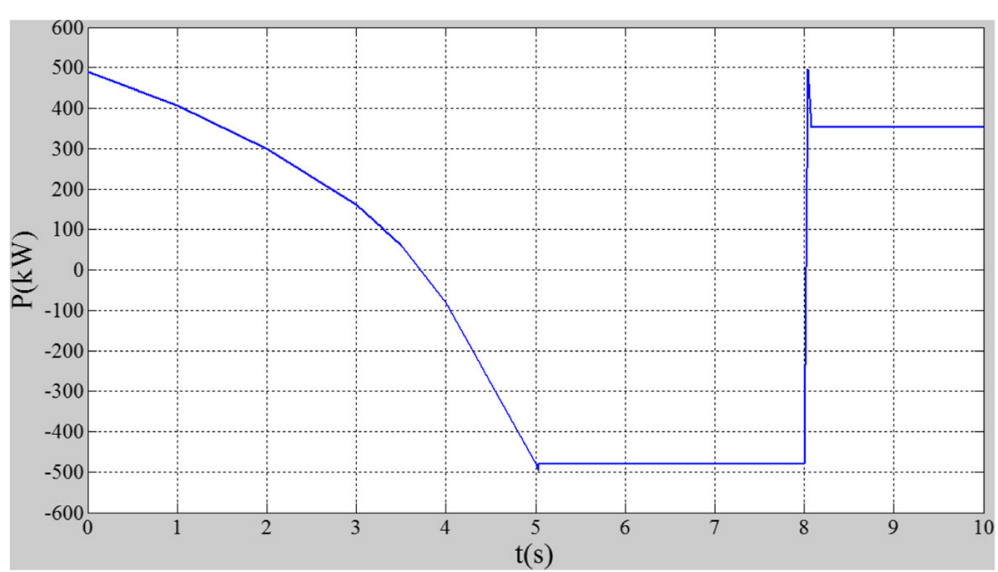

Fig. 9 Power of the double rotor speed-regulating generator. In Fig. 9, X-axis is time (s) and $Y$-axis is electrical power of the double rotor speed regulating generator $(\mathrm{kW})$ 
advanced control algorithms can also be applied to the double rotor speed-regulating wind power generation system to achieve desirable effect.

\section{Abbreviations \\ DFIG: Double-fed induction generator; PMS: Permanent magnetic synchronous generator; R\&D: Research and development}

\section{Authors' contributions}

$Y L$ is the main writer of this paper. She proposed the main idea, completed the simulation, and analyzed the result. PY and HW gave some important suggestions for this paper. All authors read and approved the final manuscript.

\section{Competing interests}

The authors declare that they have no competing interests.

\section{Publisher's Note}

Springer Nature remains neutral with regard to jurisdictional claims in published maps and institutional affiliations.

Received: 20 March 2018 Accepted: 30 May 2018

Published online: 28 June 2018

\section{References}

1. Control methodology for compensation of grid voltage unbalance using a series-converter scheme for the DFIG. Suppioni, Vinicius P. (Centro de Engenharia, Modelagem e Ci\&ecire;ncias Sociais Aplicadas, Universidade Federal Do ABC, Santo André, Brazil): Grilo, Ahda P. Teixeira, Julio C. Source: Electr. Power Syst. Res. 133, 198-208, 2016

2. L Li, H Nian, L Ding, Direct power control of DFIG system without phaselocked loop under unbalanced and harmonically distorted voltage. IEEE Trans. Energy Convers. 33, 395-405 (2018)

3. Fuzzy logic control of grid connected DFIG system using back-to-back converters. Dida, Abdelhak (Department of Electrical Engineering, Biskra University, Biskra; 07000, Algeria); Ben Attous, Djilani Source: Int. J. Syst. Assur. Eng. Manag., 8, 129-136, 2017

4. C Wu, H Nian, Stator harmonic currents suppression for DFIG based on feed-forward regulator under distorted grid voltage. IEEE Trans. Power Electron. 33, 1211-1224 (2018)

5. YW Geng, HW Liu, RX Deng, Research on a multi-objective control strategy for current-source PWM rectifiers under unbalanced and harmonic grid voltage conditions. J. Power Electron. 18, 171-184 (2018)

6. C Cheng, H Nian, Low-Complexity model predictive stator current control of DFIG under harmonic grid voltages. IEEE Trans. Energy Convers. 32, 1072-1080 (2017)

7. Dual-loop control strategy for DFIG-based wind turbines under grid voltage disturbances. Zhu, Rongwu (Department of Energy and Technology, Aalborg University, Aalborg, Denmark); Chen, Zhe; Tang, Yi; Deng, Fujin; Wu, Xiaojie Source: IEEE Trans. Power Electron., 31, 3, 2239-2253, 2016

8. AB Moreira, TAS Barros, VSC Teixeira, Power control for wind power generation and current harmonic filtering with doubly fed induction generator. Renew. Energy 107, 181-193 (2017)

9. HH Safa, M Ebrahimi, HA Zarchi, Eccentricity fault detection in permanent magnet synchronous generators using stator voltage signature analysis. Int J. Precis. Eng. Manuf. 18, 1731-1737 (2017)

10. H Ye, B Yue, X Li, Modeling and simulation of multi-scale transients for PMSG-based wind power systems. Wind Energy 20, 1349-1364 (2017)

11. K Sayed, SM Abdel, Dynamic performance of wind turbine conversion system using PMSG-based wind simulator. Electr. Eng. 99, 431-439 (2017)

12. J-Z Zhang, T Sun, F Wang, A computationally efficient quasi-centralized DMPC for back-to-back converter PMSG wind turbine systems without DClink tracking errors. IEEE Trans. Ind. Electron. 63, 6160-6171 (2016)

13. A Karakaya, K Ercument, Process time and MPPT performance analysis of CF, LUT, and ANN control methods for a PMSG-based wind energy generation system. Turk. J. Electr. Eng. Comput. Sci. 24, 3609-3620 (2016)

14. C Emanuela, P Oddo, M Drudi, Coupling hydrodynamic and wave models: first step and sensitivity experiments in the Mediterranean Sea. Ocean Dyn. 67, 1293-1312 (2017)
15. HN Das, S Kapuria, On the use of bend-twist coupling in full-scale composite marine propellers for improving hydrodynamic performance. J. Fluids Struct. 61, 132-153 (2016)

16. A novel control system design to improve LVRT capability of fixed speed wind turbines using STATCOM in presence of voltage fault. Heydari-Doostabad Hamed (Department of Electrical Engineering, Ferdowsi University of Mashhad, Mashhad, Iran); Khalghani, Mohammad Reza; Khooban, Mohammad Hassan Source: Int. J. Electr. Power Energy Syst., 77, 280-286, 2016

17. A novel wind speed estimator-integrated pitch control method for wind turbines with global-power regulation. Song, Dongran (School of Information Science and Engineering, Central South University, Changsha, China); Yang, Jian; Su, Mei; Liu, Anfeng; Cai, Zili; Liu, Yao; Joo, Young Hoon Source: Energy, 138, 816-830, 2017

18. IA Mirza, M Abdulhameed, D Vieru, Transient electro-magnetohydrodynamic two-phase blood flow and thermal transport through a capillary vessel. Comput. Methods Prog. Biomed. 137, 149-166 (2016)

19. R You, J Chai, X Sun, Experimental study on frequency support of variable speed wind turbine based on electromagnetic coupler. J. Power Electron. 12, 195-203 (2018)

20. R You, B Barahona, J Chai, Improvement of grid frequency dynamic characteristic with novel wind turbine based on electromagnetic coupler. Renew. Energy 113, 813-821 (2017)

21. N Toscani, F Grassi, G Spadacini, Transmission line and electromagnetic model of the tubular wave coupler. IEEE Trans. Electromagn. Compat. 59, 1592-1600 (2017)

\section{Submit your manuscript to a SpringerOpen ${ }^{\circ}$ journal and benefit from:}

- Convenient online submission

- Rigorous peer review

- Open access: articles freely available online

- High visibility within the field

Retaining the copyright to your article 